\title{
HUBUNGAN PENGGUNAAN ASESMEN BERBASIS PROJECT TERHADAP KEMANDIRIAN BELAJAR MURID DI SEKOLAH DASAR TEOLOGI KRISTEN PELANGI KRISTUS SURABAYA
}

\author{
Windy Franola Sine \\ Program Studi Pendidikan Guru Sekolah Dasar, \\ Universitas Kristen Petra \\ J1. Siwalankerto 121-131, Surabaya \\ E-mail: Windysine25@gmail.com
}

\begin{abstract}
ABSTRAK
Penyelenggaraan pendidikan di Indonesia perlu membangun kemandirian murid dalam belajar. Hal ini bertujuan untuk meningkatkan kualitas pendidikan agar terciptanya sumber daya manusia yang memiliki kompetensi yang utuh. Salah satu faktor kemandirian belajar adalah asesmen berbasis project. Penelitian ini bertujuan untuk mengetahui hubungan penggunaan asesmen berbasis project terhadap kemandirian belajar murid. Jenis penelitian yang digunakan adalah penelitian korelasional berdasarkan teori Sugiyono, yang dilakukan di Sekolah dasar Teologi Kristen Pelangi Kristus Surabaya. Sampel penelitian sebanyak 45 murid dengan teknik pengumpulan data menggunakan angket kuesioner. Hasil Penelitian menunjukkan bahwa terdapat hubungan yang signifikan antara asesmen berbasis project terhadap kemandirian belajar murid.
\end{abstract}

Kata kunci: Asesmen berbasis project, kemandirian belajar, metode pembelajaran, pendidikan Kristen, sekolah Kristen.

\begin{abstract}
The implementation of education in Indonesia needs to build students' independence in learning. This aims to improve the quality of education in order to create competent human resources. One of the factors for independent learning is project-based assessment. This study aims to determine the relationship between the use of project-based assessment on student learning independence. The type of research used is correlational research based on Sugiyono's theory, which was conducted at the Pelangi Christ Theology Elementary School Surabaya. The research sample consisted of 45 students with data collection techniques using a questionnaire. The results show that there is a significant relationship between project-based assessment and student learning independence.
\end{abstract}

Keywords: Christian education, Christian school, independent learning, learning methods, project based assessment.

\section{PENDAHULUAN}

Salah satu fungsi pendidikan adalah membangun kemandirian belajar. Di sekolah, kemandirian muncul ketika murid mampu untuk belajar sendiri, mempunyai kepercayaan diri yang tinggi dan selalu berusaha menghadapi masalah-masalah yang terjadi di kehidupan nyata (Aliyyah ,Puteri, \& Kurniawati,2017).

Di Indonesia, tingkat kesadaran belajar mandiri masih sangat kurang. Terbukti dari perilaku membolos, menyontek, mencari bocoran soal ujian, dan melakukan kegiatan belajar hanya menjelang ujian. Kemendikbud mencatat terdapat 126 kecurangan selama ujian nasional 2019 (Abdi,2019).

Kemandirian belajar dipengaruhi faktor internal dan faktor eksternal. Menurut
Djalia (2014), faktor internal meliputi konsep diri, motivasi, sikap, minat dan kebiasaan. Faktor eksternal meliputi keluarga, masyarakat, lingkungan sekitar, dan sekolah di mana metode pembelajaran termasuk dalam faktor eksternal tersebut.

Salah satu metode yang dapat digunakan yaitu pembelajaran berbasis proyek. Menurut Katz, metode proyek merupakan metode pembelajaran yang dilakukan untuk melakukan pendalaman tentang satu topik pembelajaran yang diminati satu atau beberapa anak (Puspitasari, 2017). Dengan diterapkannya model pembelajaran berbasis proyek diharapkan melatih kemandirian, kolaborasi dan eksperimen di dalam diri siswa atau peserta didik (Kemendikbud, 2020).

Pendidikan Kristiani secara umum bertujuan untuk mendampingi, memperlengkapi manusia agar mengalami pertumbuhan imannya secara utuh/mengalami perkembangan secara fisik, jiwa dan 
roh (Santoso,2019). Sedangkan secara khusus bertujuan untuk membentuk dan membimbing siswa agar tumbuh berkembang mencapai kepribadian utuh yang mencerminkan sebagai gambar Allah yang memiliki sifat kasih dan ketaatan kepada Tuhan, memiliki kecerdasan, keterampilan, berbudi pekerti yang luhur, kesadaran dan memelihara lingkungan hidup, serta ikut bertanggung jawab dalam pembangunan masyarakat, berbangsa dan bernegara (Intarti, 2016).

Berdasarkan hasil penelitian terdahulu, kemandirian belajar murid sangat penting untuk diperhatikan dan dikembangkan. Hal ini mendorong peneliti untuk fokus meneliti kemandirian belajar anak dengan menggunakan asesmen berbasis project. Penelitian ini penting karena proses belajar semakin terasa jika peserta didik aktif mencari dan menemukan dengan sendirinya sehingga menambah pengalaman dan wawasan. Penelitian dilakukan di SDTK Pelangi Kristus Surabaya karena memiliki visi untuk memperlengkapi anak-anak Tuhan bukan hanya dalam hal-hal akademis, tetapi juga dalam hal pembentukan karakter untuk menjadikan pelayan Tuhan yang serupa Kristus. Hal ini sejalan dengan pilar pertama sekolah yaitu mempersiapkan anak untuk mengalami proses berelasi dengan Tuhan. Berdasarkan hasil wawancara, observasi dan pengamatan melalui sosial media, menunjukkan bahwa SDTK Pelangi Kristus menerapkan pembelajaran mandiri. Murid akan melakukan project yang diberikan dan guru hanya mendamping dan memotivasi mereka (Pelangi Kristus, n.d). Hal ini menolong peneliti untuk melihat hubungan penggunaan asesmen berbasis project terhadap kemandirian belajar murid di Sekolah Dasar.

Penelitian ini bertujuan untuk menjawab pertanyaan apakah terdapat hubungan penggunaan asesmen berbasis project terhadap kemandirian belajar murid SDTK Pelangi Kristus Surabaya. Hipotesis penelitian adalah terdapat hubungan antara penggunaan asesmen berbasis project terhadap kemandirian belajar murid Sekolah Dasar Teologi Kristen Pelangi Kristus Surabaya.

\section{LANDASAN TEORI}

\subsection{Asesmen Berbasis Proyek}

Asesmen berbasis proyek adalah penilaian terhadap suatu tugas yang harus diselesaikan dalam periode/waktu tertentu, tugas tersebut berupa penyelidikan terhadap sesuatu yang mencakup perencanaan, pengumpulan data, pengorganisasian, pengolahan, dan penyajian (Sa'adah dkk, 2018). Bell (2010: 39) menjelaskan bahwa penerapan proyek dalam pembelajaran meningkatkan pemahaman terhadap topik yang dipelajari, bertanggung jawab, melatih kemandirian dan kedisiplinannya (Safaroh, 2017).

Ciri pembelajaran berbasis proyek menurut Center for Youth Development and Education Boston yaitu: 1) Siswa mengambil keputusan sendiri; 2) Siswa berusaha memecahkan sebuah masalah yang tidak memiliki satu jawaban pasti; 3) Siswa didorong untuk berpikir kritis, memecahkan masalah, berkolaborasi, serta mencoba berbagai bentuk komunikasi; 4) Siswa bertanggung jawab mencari dan mengelola sendiri informasi yang mereka kumpulkan; 5) Evaluasi dilakukan secara terusmenerus selama proyek berlangsung; 6) Siswa secara reguler merefleksikan dan merenungi yang telah mereka lakukan, baik proses maupun hasilnya (Rati, Kusmaryatni \& Rediani, 2017). Dengan demikian, guru berperan sebagai fasilitator (Wardi, 2020).

\subsection{Kemandirian Belajar}

Menurut Lilik, (2013:64), kemandirian belajar adalah suatu keterampilan belajar di mana dalam proses belajar tersebut, individu dimotivasi, dikendalikan dan dinilai oleh individu itu sendiri.

Thoha (dalam Dewi, 2018) menyebutkan faktor-faktor yang mempengaruhi kemandirian belajar yakni: 1) Faktor kematangan usia, jenis kelamin, dan intelegensi yang termasuk dalam faktor internal; 2) Faktor kebudayaan masyarakat, keluarga, sistem pendidikan di sekolah dan sistem kehidupan di masyarakat yang termasuk dalam faktor eksternal. Indikator kemandirian belajar yang dikemukakan oleh Sumarmo (2014) diantaranya sebagai berikut: 1) inisiatif belajar; 2) mendiagnosa kebutuhan belajar; 3) menetapkan target dan tujuan belajar, memonitor, mengatur dan mengontrol; 4) memandang kesulitan sebagai tantangan; 5) memanfaatkan dan mencari sumber yang relevan; 6) memilih dan menerapkan strategi belajar; 7) mengevaluasi proses dan hasil belajar; 8) self efficacy atau konsep diri.

\section{METODE PENELITIAN}

\subsection{Desain Penelitian}

Jenis penelitian yang digunakan oleh peneliti adalah kuantitatif dengan desain korelasional. Menurut Sudjana (2002:367) penelitian bersifat korelasional yaitu penelitian yang bertujuan untuk melihat sejauh mana variasi-variasi suatu faktor berkaitan dengan variasi-variasi pada satu atau lebih faktor lain berdasarkan pada koefisien korelasi (dalam Utami \& Mujahid,2018). Penelitian dilakukan di Sekolah Dasar Teologi Kristen (SDTK) Pelangi Kristus Surabaya.

3.2. Populasi, Sampel, dan Teknik Penarikan Sampel

Populasi dalam penelitian adalah seluruh siswa SDTK Pelangi Kristus Surabaya, yang berjumlah 51 orang (lihat Sugiyono, 2012, p.117). 
Jumlah sampel setelah dihitung dengan menggunakan rumus slovin adalah 45 dari total populasi 51(lihat Sugiyono, 2012, p. 118). Dikarenakan SDTK Pelangi Kristus memiliki jumlah anak di 2 kelas yang lebih sedikit dari perhitungan pada sampel, maka dilakukan pengalihan sampel sebagai berikut:

a. Kelas 1 hanya memiliki 4 siswa, maka diambil 3 siswa di kelas 3 untuk memenuhi sampel.

b. Kelas 5 hanya memiliki 5 siswa maka diambil 2 siswa dari kelas 6 untuk memenuhi sampel (lihat Sugiyono, 2012, p, 124).

3.3. Metode dan Prosedur Pengambilan Data

\subsubsection{Angket atau Kuesioner}

Metode pengumpulan data yang digunakan peneliti adalah angket atau kuesioner untuk mendapatkan data berupa angka-angka dengan pemberian skor. Soal-soal dalam kuesioner dilengkapi dengan alternatif jawaban sehingga responden tinggal memilih salah satu dari alternatif jawaban (lihat Sugiyono, 2012, p. 199). Jumlah soal dalam kuesioner asesmen berbasis proyek sebanyak 50 butir, sedangkan untuk kemandirian belajar murid adalah 60 butir.

Variabel asesmen berbasis project dan kemandirian belajar murid menggunakan skala likert dalam bentuk pilihan ganda dengan alternatif jawaban yang beda untuk mengukur sikap pendapat dan persepsi murid (lihat Sugiyono, 2012, p. 134-135).

\subsubsection{Uji Validitas}

Uji validitas menggunakan rumus korelasi product moment (lihat Sugiyono, 2014: 228) yang penghitungannya dibantu dengan program excel menggunakan rumus :

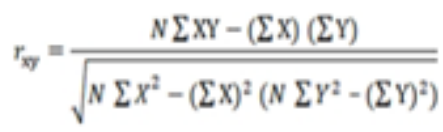

Keterangan

r XY = koefisien korelasi antara variabel $x$ dan variabel y

$\mathrm{N}=$ banyaknya subyek uji coba

$\sum \mathrm{X}=$ jumlah skor tiap butir

$\sum \mathrm{Y}=$ jumlah skor total

$\sum X 2=$ jumlah kuadrat skor tiap butir

$\sum \mathrm{Y} 2=$ jumlah kuadrat skor total

$\sum X Y=$ jumlah perkalian skor tiap butir dengan skor total

Jika $r$ hitung dikonsultasikan dengan $r$ tabel, apabila $r$ hitung $>r$ tabel maka dikatakan butir item adalah valid.

\subsubsection{Uji Reliabilitas}

Uji reliabilitas menggunakan rumus Cronbach Alpha untuk mendeteksi indikator-indikator yang tidak konsisten, sehingga indikator tersebut dapat diperbaharui lagi menjadi konsisten, yaitu :

$$
r_{i}=\frac{K}{(k-1)}\left\{1-\frac{\sum S_{i}^{2}}{S_{t}^{2}}\right\}
$$

Keterangan:

$\mathrm{ri}=$ Cronbach Alpha

$\mathrm{k}=$ Jumlah butir soal

Si 2 = variansi butir soal 76

St 2 = variansi skor total

\subsection{Teknik Analisis Data}

\subsubsection{Pengujian Persyaratan}

Peneliti menggunakan uji normalitas dan uji linieritas untuk memenuhi asumsi-asumsi yang dipersyaratkan sebelum melakukan analisis data (lihat Utami \& Mujahid, 2018). Uji normalitas data menggunakan rumus Chi Kuadrat :

$$
x^{2} \sum_{i=1}^{k} \frac{\left(\mathrm{f}_{0}-\mathrm{f}_{\mathrm{h}}\right) 2}{\mathrm{f}_{\mathrm{h}}}
$$

Keterangan :

$$
\mathrm{x} 2=\text { Chi Kuadrat }
$$

f $0=$ Frekuensi yang diperoleh dari observasi pada sampel

$\mathrm{f} \mathrm{h}=$ Frekuensi yang diharapkan dalam sampel sebagai pencerminan dari frekuensi yang diharapkan dalam populasi

Peneliti juga menggunakan uji linieritas dan keberartian regresi. Peneliti menggunakan program SPSS 26 pada komputer untuk menguji linearitas, dengan Tes Porlineariti dengan taraf signifikansi 5\% dengan keputusan dengan nilai Sig. Pada Deviation 95 from linear $\geq 0,05$ maka ada hubungan antar variabel linier. Dan jika nilai Sig pada Deviation from linearity $\leq$ 0,05 maka hubungan antar variabel tidak linear ( lihat Utami \&amp; Mujahid, 2018). Uji regresi linier data menggunakan SPSS 26 di komputer. Kriteria pengambilan keputusan menggunakan uji t yaitu jika thitung $>t$ tabel maka hipotesis diterima dan memiliki pengaruh yang signifikan.

\subsection{Uji Hipotesis}

Peneliti menggunakan rumus teknik korelasi sederhana sebagai berikut:

$$
r_{\mathrm{xy}}=\frac{N \sum \mathrm{XY}-\left(\sum \mathrm{X}\right)\left(\sum \mathrm{Y}\right)}{\sqrt{N \sum X^{2}-\left(\sum \mathrm{X}\right)^{2}\left(N \sum Y^{2}-\left(\sum \mathrm{Y}\right)^{2}\right)}}
$$

Keterangan

$\mathrm{N}$ : Jumlah responden

$\mathrm{X}$ : skor yang diberikan oleh rater 1 
Y : Skor yang diberikan oleh rater 2

\section{ANALISA DATA}

Hasil penelitian ini menunjukkan terdapat hubungan antara asesmen berbasis project terhadap kemandirian belajar murid di Sekolah Dasar Teologi Pelangi Kristus Surabaya. Dalam penelitian ini rentang skor asesmen berbasis project dan kemandirian belajar murid sama pada rentang skor sedang yaitu $71 \%$ dengan sumbangi sebesar $56,8 \%$. Dapat disimpulkan bahwa penggunaan asesmen berbasis project dapat meningkatkan kemandirian belajar murid. Sisanya dipengaruhi dari faktor lain diluar penelitian seperti konsep diri, motivasi, sikap, minat dan kebiasaan,keluarga, sekolah, masyarakat dan lingkungan sekitar.

Berdasarkan tabel variabel dapat disimpulkan bahwa rentang skor dari asesmen berbasis project lebih banyak berada pada klasifikasi skor sedang yaitu 71 $\%$. Hal ini juga sama dengan rentang skor dari kemandirian belajar murid lebih banyak berada pada klasifikasi skor sedang yaitu $71 \%$. Hasil pengujian hipotesis asesmen berbasis project terhadap kemandirian belajar murid sebagai berikut koefisien regresi $\beta=942$ dan konstanta (a) $=27,570$ serta $\mathrm{t}$ hitung sebesar 7,532 dan tingkat signifikansi sebesar 0,000 . Hal ini berarti jika tidak ada nilai koefisien asesmen berbasis project maka nilai konsisten kemandirian belajar murid adalah 27,570. Persamaan regresinya sebagai berikut $\mathrm{Y}=$ $27,570+942 \mathrm{X}$, sedangkan nilai koefisien korelasi antara asesmen berbasis project terhadap kemandirian belajar murid dengan rxy $=0,754$ yang berarti terdapat hubungan yang positif antara asesmen berbasis project terhadap kemandirian belajar murid.

Besar kontribusi asesmen berbasis project terhadap kemandirian belajar murid di Sekolah Dasar Teologi Pelangi Kristus Surabaya yaitu sebesar $56,8 \%$, sehingga disimpulkan bahwa asesmen berbasis project dan kemandirian belajar murid berhubungan positif. Hal ini berarti semakin tinggi asesmen berbasis project maka semakin tinggi juga kemandirian belajar murid, begitupun sebaliknya semakin rendah asesmen berbasis project maka semakin rendah juga kemandirian belajar murid.

Pengambilan data ini dilakukan secara online karena masa pandemi sehingga peneliti tidak dapat memantau secara langsung ketika murid mengisi kuesioner. Hal ini dapat berpotensi untuk anak memilih jawaban yang tidak sesuai dengan pengalaman maupun memilih jawaban yang dipikirkan oleh orang tua sebagai pendamping anak dalam mengisi kuesioner. Pernyataan pada setiap kuesioner yang diberikan kepada sampel yang merupakan murid kelas 1 sampai 6 SDTK Pelangi Kristus Surabaya juga sama. Hal ini dapat berpotensi membuat murid salah menafsirkan pernyataan yang ada pada kuesioner. Oleh karena itu, penelitian ini sangat terbuka untuk dibantah dan kemudian dibuktikan bahwa ada bias dalam pelaksanaan maupun hasilnya oleh penelitianpenelitian selanjutnya.

\section{KESIMPULAN DAN SARAN}

\subsection{Kesimpulan}

Kesimpulan dari penelitian ini adalah terdapat hubungan yang signifikan antara asesmen berbasis project terhadap kemandirian belajar murid.

\subsection{Saran}

Beberapa saran yang dapat peneliti berikan adalah sebagai berikut :

1. Bagi sekolah, untuk meningkatkan kemandirian belajar murid saat ini, hendaknya pihak sekolah mempersiapkan metode pembelajaran yang sesuai untuk meningkatkan kemandirian belajar murid terutama dalam masa pandemi covid-19 yang mengharuskan anak untuk belajar di rumah atau daring.

2. Bagi guru, diharapkan untuk mampu mempertimbangkan model dan metode pembelajaran yang digunakan dalam mengajar serta perlu memiliki strategi yang tepat sesuai dengan kondisi dan karakteristik murid. Hal ini dikarenakan oleh proses pembelajaran yang saat ini sedang terjadi yaitu daring yang mengharuskan anak untuk belajar secara online di rumah.

3. Bagi peneliti selanjutnya, disarankan untuk penelitian selanjutnya dapat melakukan penelitian terhadap faktor-faktor lain seperti konsep diri, motivasi, sikap, minat dan kebiasaan, keluarga, sekolah, masyarakat dan lingkungan sekitar yang dapat mempengaruhi kemandirian belajar murid terlepas dari faktor penggunaan asesmen berbasis project.

\section{DAFTAR REFERENSI}

Abdi, A. P. (2019). Kemendikbud catat 126 kecurangan selama Ujian Nasional 2019. Tirto.ID. Retrieved from https://tirto.id/kemendikbudcatat-126- kecurangan-selama-ujian-nasional2019-drNd

Aliyyah, R. R., Puteri, F. A., \& Kurniawati, A. (2017). Pengaruh kemandirian belajar terhadap hasil belajar IPA. Jurnal Sosial Humaniora, 8(2), 126-143. https://doi.org/10.30997/jsh.v8i2.886

Aulia, L. N., Susilo, \& Subali, B. (2018). Perbandingan model problem based learning berbantuan Edmodo terhadap kemandirian belajar dan pemahaman konsep fluida dinamis. UPEJ Unnes Physics Education Journal, 7(2), 73-84. https://doi.org/10.15294/upej.v7i2.27470 
Dewi, Y. P. (2018). Pengaruh model pembelajaran problem posing terhadap kemandirian belajar siswa pada pelajaran akuntansi di Sekolah Menengah Atas Negeri 6 Tualang Kabupaten Siak (Undergraduate thesis. Universitas Islam Negeri Sultan Syarif Kasim Riau). Retrieved from http://repository.uinsuska.ac.id/14224/

Ekawati, N. P. N., Dantes, N., \& Marhaeni, A. A. I. N. (2019). Pengaruh model project based learning berbasis $4 \mathrm{c}$ terhadap kemandirian belajar dan kemampuan membaca pemahaman pada siswa kelas iV SD Gugus III Kecamatan Kediri Kabupaten Tabanan. PENDASI: Jurnal Pendidikan Dasar Indonesia, 3(1), 4151.

https://doi.org/10.23887/jpdi.v3i1.286 $\underline{6}$

Fahradina, N., Ansari, B. I., \& Saiman. (2014). Peningkatan kemampuan komunikasi matematis dan kemandirian belajar siswa SMP dengan menggunakan model investigasi kelompok. Jurnal Didaktik Matematika, 1(2), 54-64. Retrieved from http://jurnal.unsyiah.ac.id/DM/article/ view/2077

Hidayat, F., Akbar, P., \& Bernard, M. (2019). Analisis kemampuan berfikir kritis matematik serta kemandiriaan belajar siswa SMP terhadap materi SPLDV. Journal on Education, 1(2), 515-523. https://doi.org/10.31004/joe.v1i2.106

Intarti, E. R. (2016). Peran guru pendidikan agama Kristen sebagai motivator. REGULA FIDEI: Jurnal Pendidikan Agama Kristen, 1(2), 28-40. Retrieved from http://christianeducation.id/ejournal/index.php/regulafidei/article/d ownload/12/12

Kemendikbud. (2020). Project based learning model pembelajaran. Retrieved from https://lpmplampung.kemdikbud.go.id/ detailpost/project-based-learningmodel-pembelajaran-bermakna-dimasa-pandemi-covid-19

Kurniawan, H. R., Elmunsyah, H., \& Muladi, M. (2018). Perbandingan penerapan model Pembelajaran Project Based Learning (PJBL) dan Think Pair Share (TPS) berbantuan modul ajar terhadap kemandirian dan hasil belajar rancang bangun jaringan. Jurnal Pendidikan (Teori Dan Praktik), 3(2),
80-85. https://doi.org/10.26740/jp.v3n2.p8085

Malik, A., Rosidin, U., \& Ertikanto, C. (2018). Pengembangan instrumen asesmen HOTS fisika SMA menggunakan model Inkuiri Terbimbing. Jurnal Lentera Pendidikan Pusat Penelitian LPPM UM METRO, 3(1), 11-25. Retrieved from

https://ojs.ummetro.ac.id/index.php/lentera/arti cle/view/733

Marfuati, R. (2019). Hubungan konsep diri dan persepsi pola asuh authoritative dengan kemandirian belajar pada siswa. (Naskah Publikasi Program Studi Magister PsikologiSains). Retrieved from http://eprints.mercubuana- yogya.ac.id/4863/

Murdaningsih, D. (2019). Rendahnya kompetensi guru jadi masalah pendidikan Indonesia. Republika Online. Retrieved from https://republika.co.id/berita/pq53k5368/renda hnya-kompetensi-guru-jadi- masalahpendidikan-indonesia

Nasution, T. (2018). Membangun kemandirian siswa melalui pendidikan karakter. IJTIMAIYAH: Jurnal Ilmu Sosial Dan Budaya, 2(1), 1-18. Retrieved from http://jurnal.uinsu.ac.id/index.php/ijtimaiyah/ar ticle/view/2925

Ni'mah, F. (2018). Implementasi metode pembelajaran yang humanis untuk meningkatkan kemandirian belajar siswa kelas II (dua) Madrasah Ibtidaiyyah NU Sholahiyah Pedawang Kudus tahun 2017/2018 (Undergraduate thesis. Institut Agama Islam Negeri Kudus). Retrieved from http://repository.iainkudus.ac.id/2454/

Nofrion. (2018). PBL dan PjBL dalam pembelajaran geografi. https://doi.org/10.31227/osf.io/9p4gb

Nuryadi, \&amp; Rahmawati, P. (2018). Persepsi siswa tentang penerapan model pembelajaran berbasis proyek ditinjau dari kreativitas dan hasil belajar siswa. Jurnal Mercumatika: Jurnal Penelitian Matematika Dan Pendidikan Matematika, 3(1), 53-62. https://doi.org/10.26486/jm.v3i1.656

Pakpahan, R. (2017). Faktor-faktor yang memengaruhi capaian literasi matematika siswa Indonesia dalam PISA 2012. Jurnal Pendidikan Dan Kebudayaan, 1(3), 331-347. https://doi.org/10.24832/jpnk.v1i3.496

Pelangi Kristus, (n.d). Visi dan misi Pelangi Kristus. Retrieved from https://pelangikristus.or.id/academics/.

Purwanto, (2017). Instrumen Penelitian Sosial dan Pendidikan: Pengembangan dan pemanfaatan. Yogyakarta: Pustaka Pelajar. Retrieved from http://library.fip.uny.ac.id/opac/index.php?p=s how_detail\&amp;id=4451.

Puspitasari, R. D. (2017). Pengaruh pembelajaran berbasis proyek terhadap kemandirian belajar 
fisika peserta didik kelas X SMKN 7 Bandar Lampung (Undergraduate thesis, UIN Raden Intan Lampung). Retrieved from http://repository.radenintan.ac.id/1954/

Sa’adah, D., Masrukan, M., \& Mariani, S. (2018). Kemampuan berpikir kritis siswa SMK ditinjau dari jiwa kewirausahaan pada project based learning dengan asesmen proyek. In Prosiding Seminar Nasional Pascasarjana, 1(1), 9-14. Retrieved from

https://proceeding.unnes.ac.id/index.p hp/snpasca/article/view/169.

Safaroh, R. (2017). Pengembangan asesmen autentik berbasis proyek untuk mengukur hasil belajar siswa SMP kelas VII pada tema panas (Undergraduate thesis, Universitas Negeri Semarang). https://lib.unnes.ac.id/31664/

Sipayung, T. F. (2016). Pengembangan instrumen asesmen sikap sosial pada materi pemisahan campuran (Undergraduate thesis. Universitas Lampung). Retrieved from http://digilib.unila.ac.id/24568/.

Santoso, S. (2019). Pendidikan Kristen konteks sekolah: 12 pesan untuk guru dan pengelola. Jurnal Abdiel: Khazanah Pemikiran Teologi, Pendidikan Agama Kristen dan Musik Gereja, 3(1), 77-79. https://doi.org/10.37368/ja.v3i1.38.

Sugiyono (2012). Metode penelitian pendidikan: pendekatan kuatitatif, kualitatif, dan $R \& D$. Bandung:Alfabeta.

Sugiyono (2017). Metode penelitian pendidikan: Pendekatan kuatitatif, kualitatif, dan $R \& D$. Bandung:Alfabeta.

Suid \& Syafrina, A. (2017). Analisis kemandirian siswa dalam proses pembelajaran di Kelas III SD Negeri 1 Banda Aceh. Jurnal Pesona Dasar, 1(5), $\quad$ 70-81. http://www.jurnal.unsyiah.ac.id/PEAR $\underline{\text { index }}$

Sumantri, M. S. (2016). Asesmen dan intervensi pedagogik dalam membangun generasi emas ditinjau dari perspektif pengembangan kreativitas siswa kelas awal sekolah dasar. Jurnal Pendidikan Dasar, 7(1), 74-89.

https://doi.org/10.21009/JPD.071.07
Susilowati, A. (2018). Pengaruh PBL terhadap kemandirian belajar siswa SD. Indonesian Journal of Primary Education, 2(1), 72-77. https://doi.org/10.17509/ijpe.v2i1.9392

Tani, J., Setiasih, O., \& Mariyana, R. Pengaruh metode proyek terhadap kemandirian anak. Edukids: Jurnal Pertumbuhan, Perkembangan, dan Pendidikan Anak Usia Dini, 14(2), 396$409 . \quad$ Retrieved from https://ejournal.upi.edu/index.php/edukid/articl e/view/20031/10168

Utami, A. P., \& Mujahid, I. (2018). Hubungan antara kecerdasan spiritual, motivasi belajar dan manajemen belajar dengan prestasi belajar mata pelajaran PAI siswa kelas VII SMPN 2 Manisrenggo Klaten 2017/2018 (Undergraduate thesis, Institut Agama Islam Negeri Surakarta). Retrieved from https://onesearch.id/Record/IOS3440.1896

Wahono, J. (2019). Pengaruh bimbingan belajar terhadap kemandirian belajar siswa SDN 025 Rambah Hilir. Instructional Development Journal, 2(1), 30- 37. http://dx.doi.org/10.24014/idj.v2i1.7870

Wahyuningsih, N. (2017). Peningkatan kemandirian belajar matematika dan kemampuan koneksi matematis siswa dengan model pembelajaran CORE pada siswa kelas VII-A SMPN 30 Purworejo tahun pelajaran 2016/2017. Jurnal pendidikan matematika. Retrieved from http://ejournal.umpwr.ac.id/index.php/ekuivale n/article/view/4224

Wardani, E.K. (2016). Pengaruh disiplin dan kemandirian terhadap prestasi belajar siswa kelas atas SD Muhammadiyah 3 Nusukan Tahun 2015/2016 (Undergraduate thesis. Universitas Muhammadiyah Surakarta). Retrieved from http://eprints.ums.ac.id/41280/

Widodo, F. P. (2017). Desain student practical worksheet berbasis project based learning untuk indentifikasi keterampilan proses sains materi koloid kelas XI SMA (Undergraduate thesis, Universitas Negeri Semarang). Retrieved from https://lib.unnes.ac.id/32192/

Yuliani, R., Praja, E. S., \& Noto, M. S. (2018). Pengaruh model pembelajaran missouri mathematics project terhadap kemampuan koneksi matematis dan kemandirian belajar siswa SMP. Jurnal Elemen, 4(2), 131. http://doi.org/ : 10.29408/jel.v4i2.478

Yuliana, C. (2020). Project based learning, model pembelajaran bermakna di masa pandemic. Retrieved from http://lpmplampung.kemdikbud.go.id/pocontent/uploads/PjBL edit_cecil_052020.pdf

Yusuf, M. A (2015). Asesmen dan Evaluasi Pendidikan: Pilar penyedia informasi dan kegiatan pengendalian mutu pendidikan. Jakarta: Kencana. Retrieved from https://books.google.co.id/books?hl=id\&amp;ir 
Aletheia Christian Educators Journal, Vol. 2, No. 2, Oktober 2021, 157-163

=\&amp;id=rlY_DwAAQBAJ\&amp;oi =fnd \&amp;pg=PR23\&amp;dq

Yatmoko, F. D. (2018). Penerapan model pembelajaran kooperatif tipe STAD untuk meningkatkan kerjasama dan hasil belajar matematika materi volume kubus dan balok kelas v SDK Murukan tahun pelajaran 2017/2018

(Undergraduate thesis, Universitas Sanata Dharma, 2018). Retrieved from http://repository.usd.ac.id/31392/ 